\title{
Early antibiotic treatment of reactive arthritis associated with enteric infections: clinical and serological study
}

\author{
Aril Frydén, Ann Bengtsson, Ulla Foberg, Bo Svenungsson, Birgitta Castor, Anders Kärnell, \\ Robert Schvarcz, Bertil Lindblom, Erik Kihlström
}

\begin{abstract}
Objective-To find out whether a 10-14 days' course of antibiotics early in the course of reactive arthritis associated with enteric infections could reduce the severity and duration of the disease and whether the antibody response in patients with reactive arthritis associated with yersinia infection differed between those treated and those not treated with the antibiotics.
\end{abstract}

Design-Prospective multicentre trial in which patients were randomised to treatment or no treatment with antibiotics. Patients were seen at three and six weeks and three, six, nine, 12 , and 18 months after their first visit.

Setting-Departments of infectious diseases in three hospitals in Linköping, Malmö, and Stockholm, Sweden.

Patients -40 Consecutive patients who had had symptoms of reactive arthritis associated with enteric infection for less than four weeks.

Interventions - 20 Patients were allocated to treatment with antibiotics and 20 patients did not receive antibiotics. All patients received non-steroidal antiinflammatory drugs, and four also received intraarticular steroid injections after at least six weeks' observation.

Main outcome measures-Arthritic symptoms assessed clinically and by using Ritchies? index; blood measurements reflecting inflammatory activity; serum IgG, IgM, and IgA antibody titres; HLA tissue type.

Results - No difference was observed concerning duration of arthritis, grade of inflammation, and number of joints affected between patients treated and those not treated with antibiotics. Furthermore, there was no significant difference between the two groups in erythrocyte sedimentation rate and haptoglobin, IgG, and IgA concentrations. All values had returned to normal within three months. No patient developed chronic arthritis, but sustained slight arthralgia occurred in three patients. The HLA-B27 antigen was found in $23(58 \%)$ of the patients, and its presence did not affect clinical outcome. The IgG, IgM, and IgA antibody responses were similar in patients treated with antibiotics and those not treated.

Conclusion-Short term antibiotic treatment has no beneficial effect on the clinical outcome of reactive arthritis associated with enteric infection.

\section{Introduction}

Reactive arthritis is mostly associated with sexually transmitted diseases, mainly those caused by Chlamydia trachomatis, and with enteric infections due to yersinia, campylobacter, salmonella, and shigella species. The pathogenesis of reactive arthritis is still obscure in spite of intensive investigations. Studies on reactive arthritis associated with Yersinia enterocolitica have suggested an aberrant immune reponse to, and intracellular persistence of, yersinia in the intestinal epithelium and reticuloendothelial tissue with induction of a prolonged antibody response.'

The potential causative micro-organisms have only occasionally been cultured from the faeces of patients with reactive arthritis. ${ }^{1}$ Recently, however, studies reported that yersinia antigens could be detected by immunofluorescence in epithelial cells from intestinal biopsy samples, reticuloendothelial cells, synovial cells, and leucocytes from synovial fluid in patients with reactive arthritis and chronic yersinia infections. ${ }^{23}$ Arthritic symptoms may also occur in patients with negative results on agglutination. ${ }^{2}$ Persistence of both $\operatorname{IgG}$ and $\operatorname{IgA}$ antibodies, however, has been shown by immunoblotting in patients with negative test results by conventional serological methods. ${ }^{24}$ These findings support the theory that yersinia is involved in the pathogenesis of reactive arthritis and is present in patients with prolonged symptoms.

The treatment of reactive arthritis comprises mainly non-steroidal anti-inflammatory drugs, intra-articular steroid injections, and physical treatment. The role of antibiotics in the treatment is controversial, and there are no controlled studies that prove their effect. It seems reasonable that early treatment with antibiotics would prevent intracellular persistence of the microorganisms. Improvement in patients with chronic symptoms of arthritis that developed after infectious enterocolitis was reported in an uncontrolled study with antibiotic treatment for several months. ${ }^{5}$ In a recent study with antibiotic treatment for four to 10 weeks clinical improvement indicated by the concomitant disappearance of yersinia antigens in intestinal biopsy samples and the disappearance of serum antibodies to yersinia was recorded. ${ }^{2}$ In a retrospective follow up study, however, no appreciable difference in outcome with regard to arthritic symptoms could be found between patients who were or were not given antibiotics. ${ }^{6}$

The main purposes of the present, completely randomised prospective investigation were to find out, firstly, whether a 10-14 days' course of antibiotics early in the development of reactive arthritis associated with enteric infections could reduce the severity and duration of the disease compared with no antibiotic treatment, and, secondly, whether the antibody response in patients with reactive arthritis associated with yersinia differed between treated and untreated patients.

\section{Patients and methods}

During 1984-8, 40 consecutive patients with reactive arthritis after enteric infection caused by 
$Y$ enterocolitica and salmonella, campylobacter, or shigella species entered this prospective multicentre study. The aetiological diagnosis was based on a positive faecal culture (for salmonella, campylobacter, and shigella) or positive results of serology tests (for $Y$ enterocolitica), or both. The number of patients required for the study was predetermined by considering the expected effects of treatment. The patients were completely randomised to antibiotic treatment (for 10-14 days) or no treatment (table I) by using a table of random numbers. The groups obtained were reasonably comparable with respect to relevant prognostic variables. Treatment was started immediately. Both patients and investigators were aware of the treatment employed. Patients aged less than 15 years and those who had had arthritic symptoms for more than four weeks were excluded from the study. The study was approved by the relevant ethical committees.

TABLE I-Antibiotic treatment in 20 patients with reactive arthritis associated with enteric infections

\begin{tabular}{|c|c|c|c|}
\hline \multirow[b]{2}{*}{ Antibiotics } & \multicolumn{3}{|c|}{ Infecting organism } \\
\hline & $Y$ enterocolitica & Salmonella & Campylobacter \\
\hline $\begin{array}{l}\text { Pivampicillin and } \\
\text { pivmecillinam }\end{array}$ & & 4 & \\
\hline Doxycycline & 6 & & \\
\hline $\begin{array}{l}\text { Erythromycin } \\
\text { Trimethoprim and }\end{array}$ & & & 2 \\
\hline $\begin{array}{l}\text { sulphamethoxazole } \\
\text { Pivmecillinam }\end{array}$ & $\begin{array}{l}5 \\
2\end{array}$ & & \\
\hline Cinoxacin & & 1 & \\
\hline
\end{tabular}

All but four patients had not been taking antibiotics for at least one week when randomised. Two patients in the treatment group had received cloxacillin and penicillin $G$, respectively, and one patient in the non-treatment group had received cefuroxime and one cloxacillin and penicillin $\mathrm{V}$ for two days before inclusion in the study. These patients were included in the study as cloxacillin and penicillin have an inappropriate effect on $Y$ enterocolitica and because the microorganism could still be cultured from the stool in the patient who had received cefuroxime for one day (an antibiotic to which $Y$ enterocolitica is sensitive). All patients were treated with non-steroidal anti-inflammatory drugs, and four patients also received intraarticular steroid injections after at least six weeks' observation.

\section{FOLLOW UP}

Patients were seen at three and six weeks and three, six, nine, 12 , and 18 months after the first visit. Blood samples were taken for analysis of haemoglobin concentration, white blood cell and platelet counts, erythrocyte sedimentation rate, potassium, sodium, and creatinine concentrations, and aspartate aminotransferase and alanine aminotransferase activities before randomisation and at each visit. Serum electrophoresis (for separation of haptoglobin, orosomucoid, $\operatorname{IgG}, \operatorname{Ig} M$, and $\operatorname{Ig} A$ ) was performed at the first visit and at least three times subsequently. HLA class I antigens were determined with a cytotoxic two step technique modified for Hamar trays. Tests for antinuclear antibodies and rheumatoid factor were performed. Faecal cultures were obtained at each visit until they yielded negative results. Blood samples for determination of antibodies against yersinia, salmonella, and campylobacter were taken at each visit or until results were negative (see below). Throat cultures (for growth of $\beta$-haemolytic streptococci) were obtained in all patients. Cultures for growth of Chl trachomatis and Neisseria gonorrhoeae were obtained in all men but four younger than 30 years of age. Patients' joints were examined at each visit, and joint tenderness was assessed using Ritchie's index, which is based on the sum of tenderness of affected joints. ${ }^{\star}$
BACTERIAL ANTIGENS AND ENZYME LINKED IMMUNOSORBENT ASSAY (ELISA)

Lipopolysaccharides extracted with hot phenol and water ${ }^{9}$ from $Y$ enterocolitica $\mathrm{O}$ antigen 3, S typhimurium ( $\mathrm{O}$ antigens 4 and 5 ), and $S$ enteritidis (O antigen 9 ) were obtained from the National Bacteriological Laboratory, Stockholm, Sweden. Microtitre plates (Dynatech, Plochingen, Germany) were coated with lipopolysaccharides $10 \mathrm{mg} / \mathrm{ml}$ at $\mathrm{pH} 9.6$ overnight at room temperature. Serum samples diluted 1 in 1000 in phosphate buffered saline $(\mathrm{pH} \mathrm{7.3)}$ and $0.05 \%$ Tween 20 were added. For determination of $\operatorname{IgG}$ and $\operatorname{Ig} \mathrm{A}$ concentrations the plates were incubated at room temperature for one hour; for determination of $\operatorname{IgM}$ they were incubated at $37^{\circ} \mathrm{C}$ for two hours. After washing three times with sodium chloride and Tween, swine antihuman $\operatorname{IgG}, \operatorname{IgM}$, or $\operatorname{IgA}$ conjugated with alkaline phosphatase (Orion Diagnostica Espoo, Finland) was added. The plates were incubated overnight at room temperature and washed four times in sodium chloride and Tween. Freshly prepared p-nitrophenylphosphate (Sigma, St Louis, Missouri, United States) was added, and the plates were incubated at room temperature until control serum samples had reached their predetermined optical densities at $410 \mathrm{~nm}$. The antibody titre is expressed as the optical density multiplied by the serum dilution factor-that is, 1000 . Based on values on healthy controls a value higher than 500 was considered a positive result.

The antibody response to campylobacter was investigated by using an acid extracted antigen preparation in a diffusion-in-gel enzyme linked immunosorbent assay (ELISA). ${ }^{10}$

Statistical analyses-Student's $t$ test and the MannWhitney rank sum test were applied. The $\chi^{2}$ test with Yates's correction was used for group comparisons when dichotomous variables were considered. When comparing patients treated and those not treated with antibiotics with respect to duration of reactive arthritis data were stratified with respect to their HLA-B27 state in order to avoid a possible bias in the comparison. Rank sum tests were carried out separately in patients who were negative and in patients who were positive for HLA-B27 antigen. Results from these separate groups were then combined using the weighting procedure given by Lehman.

\section{Results}

The group treated with antibiotics comprised 20 patients ( 10 women) with a mean age of 47 years (range 22-84 years). The group not treated with antibiotics comprised 20 patients (nine women) with a mean age of 42 years (range $22-79$ years).

\section{BACTERIAL AETIOLOGY}

The causative agent in 13 of the treated patients was $Y$ enterocolitica $\mathrm{O}$ antigen 3 (including seven with positive cultures), salmonella species in five patients, and Campylobacter jejuni or $C$ coli in two.

The aetiology in the untreated patients was $Y$ enterocolitica $\mathrm{O}$ antigen 3 in 14 patients (including eight who with positive cultures), Shigella flexneri in one, salmonella species in four, and $C$ jejuni or $C$ coli in one. Throat cultures for $\beta$-haemolytic streptococci were negative in all patients, as were cultures for $C h l$ trachomatis and $N$ gonorrhoeae.

\section{SYMPTOMS AND COURSE OF DISEASE}

In all, 35 out of 40 patients had a history of intestinal symptoms (diarrhoea or abdominal pain, or both). The median number of days from the start of intestinal symptoms to the first visit was 19 (range 3-55 days) and between the start of intestinal symptoms and the development of reactive arthritis nine (range 0-59 
TABLE II - Median (range) maximum values and duration of increased value of Ritchie's index, maximum number of joints affected, and duration of arthritic symptoms in 40 patients with reactive arthritis who were or were not given antibiotics

\begin{tabular}{lccc}
\hline & $\begin{array}{c}\text { Treated with antibiotics } \\
(\mathbf{n}=20)\end{array}$ & $\begin{array}{c}\text { Not treated with } \\
\text { antibiotics }(\mathbf{n}=20)\end{array}$ & 95\% Confidence interval \\
\hline $\begin{array}{l}\text { Maximum Ritchie's index } \\
\text { Duration of increased Ritchie's } \\
\text { index (weeks) }\end{array}$ & $4(0-22)$ & $6(0-13)$ & 0 to +4 \\
$\begin{array}{l}\text { Maximum number of affected } \\
\text { joints }\end{array}$ & $12(0-72)$ & $12(0-36)$ & -6 to +9 \\
$\begin{array}{l}\text { Duration of reactive arthritis } \\
\text { (weeks) }\end{array}$ & $3(1-7)$ & $3(1-12)$ & -1 to +1 \\
\hline
\end{tabular}

TABLE III -Sex, HLA-B27 state, and joints affected in patients with and without antibiotic treatment. Values are numbers of patients (number with bilateral âffected joints)

\begin{tabular}{|c|c|c|}
\hline & $\begin{array}{l}\text { Treated } \\
\text { with } \\
\text { anti- } \\
\text { biotics }\end{array}$ & $\begin{array}{l}\text { Not } \\
\text { treated } \\
\text { with } \\
\text { anti- } \\
\text { biotics }\end{array}$ \\
\hline $\operatorname{Sex}(M / F)$ & $10 / 10$ & $11 / 9$ \\
\hline $\begin{array}{l}\text { Positive for } \\
\text { HLA-B27 }\end{array}$ & & \\
\hline Knee & $13(5)$ & $11(7)$ \\
\hline Ankle & $10(3)$ & $12(5)$ \\
\hline $\begin{array}{l}\text { Metatarso- } \\
\text { phalangeal }\end{array}$ & $8(2)$ & $4(2)$ \\
\hline Hip & 1 & $1(1)$ \\
\hline Metacarpo- & & \\
\hline phalangeal & 1 & $6(3)$ \\
\hline Sacroiliac & $5(2)$ & $2(1)$ \\
\hline Elbow & 1 & $2(1)$ \\
\hline Wrist & $2(1)$ & $2(1)$ \\
\hline $\begin{array}{l}\text { Proximal inter- } \\
\text { phalangeal }\end{array}$ & 1 & 1 \\
\hline
\end{tabular}
symptoms was found between treated and untreated duration of symptoms was appreciably longer $(\mathrm{p}=0.0096)$ in those positive for HLA-B27 than in those negative for it (median values 24 and three weeks, respectively).

Erythema nodosum was noticed in four treated and three untreated patients. All of these patients were negative for HLA-B27. Symptoms of the urogenital tract (urgency and pain of micturition) were reported by one treated and two untreated patients. Microscopic haematuria was found in one treated and one untreated patient. Conjunctivitis or acute anterior uveitis, or both, were observed in three treated and in three untreated patients.

\section{LABORATORY INVESTIGATIONS}

No significant differences were found between treated and untreated patients with respect to initial and maximum values of erythrocyte sedimentation rate; serum haptoglobin, IgG, and IgA concentrations;

TABLE IV - Mean $(S D)$ maximum values of erythrocyte sedimentation rate and haptoglobin, orosomucoid, IgG, and IgA concentrations and minimum haemoglobin concentration in patients with reactive arthritis

\begin{tabular}{lrr}
\hline & $\begin{array}{c}\text { Treated with } \\
\text { antibiotics }\end{array}$ & \multicolumn{1}{c}{$\begin{array}{c}\text { Not treated with } \\
\text { antibiotics }\end{array}$} \\
\hline $\begin{array}{l}\text { Erythrocyte sedimentation } \\
\text { rate }(\text { mm in first hour })\end{array}$ & $61(26)(\mathbf{n}=20)$ & $73(25) \quad(\mathbf{n}=20)$ \\
Haemoglobin $(\mathbf{g} / \mathbf{l})$ & $122(11)(\mathbf{n}=20)$ & $120(12)(\mathbf{n}=20)$ \\
Haptoglobin $(\mathbf{g} / \mathbf{l})$ & $3 \cdot 4(1 \cdot 8)(\mathbf{n}=18)$ & $4 \cdot 4(1 \cdot 4)(\mathbf{n}=20)$ \\
Orosomucoid $(\mathbf{g} / \mathbf{l})$ & $1 \cdot 6(0 \cdot 7)(\mathbf{n}=16)$ & $2 \cdot 2(0 \cdot 6)^{\star}(\mathbf{n}=19)$ \\
IgG $(\mathrm{g} / \mathbf{l})$ & $12 \cdot 4(2 \cdot 8)(\mathbf{n}=18)$ & $11 \cdot 3(1 \cdot 8)(\mathbf{n}=20)$ \\
IgA $(\mathrm{g} / \mathbf{l})$ & $2 \cdot 9(1 \cdot 4)(\mathbf{n}=18)$ & $3 \cdot 5(2 \cdot 2) \quad(\mathbf{n}=20)$ \\
\hline
\end{tabular}

${ }^{\star} \mathrm{p}=0 \cdot 0066$ (Student's $t$ test $)$.

TABLE V-Persistence of IgG, IgM, and IgA antibodies against " $Y$ enterocolitica" $O$ antigen 3 in patients with reactive arthritis who were or were not treated with antibiotics. Values are numbers of patients with antibodies

\begin{tabular}{|c|c|c|c|c|c|c|c|c|c|}
\hline & \multicolumn{3}{|c|}{ At $1-2$ months } & \multicolumn{3}{|c|}{ At 6-8 months } & \multicolumn{3}{|c|}{ At $>12$ months } \\
\hline & $\mathrm{IgG}$ & $\operatorname{Ig} M$ & $\overline{I g A}$ & $\mathrm{IgG}$ & $\operatorname{Ig} M$ & $\operatorname{Ig} A$ & $\operatorname{IgG}$ & $\operatorname{Ig} M$ & $\operatorname{Ig} \mathrm{A}$ \\
\hline Treated patients & $13 / 13$ & $12 / 13$ & $10 / 13$ & $7 / 12$ & $5 / 12$ & $0 / 12$ & $4 / 12$ & $2 / 12$ & $0 / 12$ \\
\hline Untreated patients & $14 / 14$ & $14 / 14$ & $11 / 14$ & $12 / 14$ & $5 / 14$ & $1 / 14$ & $5 / 14$ & $2 / 14$ & $0 / 14$ \\
\hline
\end{tabular}

and minimum haemoglobin concentration (table IV). The concentration of orosomucoid was significantly $(p=0.0066)$ higher in the untreated group. All values became normal within three months. Platelet counts and creatinine and albumin concentrations were normal in all patients. Tests for rheumatoid factor and antinuclear antibodies yielded negative results in all patients.

\section{Y ENTEROCOLITICA SEROLOGY}

The magnitude and duration of the serological response were evaluated with respect to HLA-B27 state, antibiotic treatment, and whether the patient had a culture that was positive for $Y$ enterocolitica. Patients were followed up for a median of 12 months (range 2-60 months).

A gradual decrease in the number of patients with antibodies against $Y$ enterocolitica was seen over time. There were variations, however, among the prevalences of the different classes of immunoglobulins with time (table V). In all, nine out of $26(35 \%)$ patients still had IgG antibodies after 12 months, whereas by then none had IgA antibodies. The IgG antibody response also persisted longer than the IgM response. No difference in antibody persistence calculated as half life was found between those treated and those not treated with antibiotics (table VI). This was true also when the persistence and half life of the antibody response were separately evaluated for individual patients with positive or negative cultures.

TABLE VI-Median (range) half life of IgG, IgM, and IgA titres against " $Y$ enterocolitica" $O$ antigen 3 in patients with reactive arthritis who were or were not treated with antibiotics

\begin{tabular}{lccc}
\hline & \multicolumn{3}{c}{ Half life (months) } \\
\cline { 2 - 4 } & IgG & IgM & IgA \\
\hline Treated patients & $4(2->48)^{\star}$ & $2(1-4)$ & $1(1->14)^{\star}$ \\
Untreated patients & $4(1->14)^{\star}$ & $2(1-3)$ & $1(1-6)$ \\
\hline
\end{tabular}

${ }^{\star}$ Range is not specified because the half life was not reached within follow up period; this did not affect median values.

TABLE VII-Median (range) peak values of IgG, IgM, and IgA antibodies against " $Y$ enterocolitica" $O$ antigen 3 expressed as optical density $\times 1000$ in patients with reactive arthritis with relation to outcome of faecal culture for yersinia

\begin{tabular}{llll}
\hline & \multicolumn{3}{c}{ Peak relative titre $(\text { optical density } \times 1000)^{\star}$} \\
\cline { 2 - 3 } Faecal culture & $\operatorname{IgG}$ & $\operatorname{IgM}$ & $\operatorname{IgA}$ \\
\hline Postive & $2685(850-3220)$ & $2780(1240-3190)$ & $2240(290-2820) \dagger$ \\
Negative & $2670(540-3010)$ & $1820(300-3210)$ & $520(150-2760)$ \\
\hline
\end{tabular}

$\star$ Values $>500$ were considered positive results.

$t \mathrm{p}=0.020$ (Mann-Whitney rank sum test) compared with patients with a negative culture.

Patients with a positive faecal culture of $Y$ enterocolitica had higher peak IgA concentrations (measured as optical density $\times 1000)(2240$; range $290-2820)$ compared with those with a negative culture $(520$; range 150-2760) $(p=0 \cdot 020)$ (table VII). These differences were even more pronounced if only patients who were not given antibiotics were considered and not seen at all in patients treated with antibiotics (data not given).

No significant influence of the presence of the HLAB27 antigen on the antibody responses was detected (data not given).

When the evaluation was extended also to include patients with salmonella or campylobacter infections the serological responses were comparable with those in patients with $Y$ enterocolitica infections.

\section{Discussion}

The risk of developing reactive arthritis varies considerably depending on both the micro-organisms 
concerned and individual predisposing factors such as the presence of HLA-B27. ${ }^{12}$ Frequencies of $2-50 \%$ (mostly $10 \%$ ) have been reported for yersinia infections. ${ }^{12} \mathrm{~A}$ frequency of about $3 \%$ has been given for shigella, salmonella, and campylobacter infections, even though there is considerable variation from one epidemic to another. ${ }^{13}$ The distribution of the aetiological agents found in this investigation, with a predominance of yersinia $(27 / 40)$, followed by salmonella (9/40), campylobacter (3/40), and shigella $(1 / 40)$, seems to reflect reasonably the true condition in a non-epidemic situation. ${ }^{14}$ All $Y$ enterocolitica isolates were $\mathrm{O}$ antigen 3 , which is the predominant serotype in the Scandinavian countries.

The severity of arthritis on admittance was similar in those treated with antibiotics and those not treated. No beneficial effect of antibiotic treatment was found when grade of inflammation, maximum number of affected joints, maximum Ritchie's index, and duration of arthritic symptoms were compared in the treated and untreated patients. Antibiotics did not shorten the duration of half life of the antibody response in patients with reactive arthritis.

A major predisposing condition for reactive arthritis is the presence of HLA-B27. This antigen was found in $58 \%$ of patients. This figure is slightly lower than those reported previously but is still high compared with that of $8 \%$ seen in the population in Sweden. ${ }^{12}$

Previous retrospective investigations have shown that patients positive for HLA-B27 have a more severe disease. ${ }^{15}$ This was not confirmed in our prospective study. Nor did we show any significant difference in antibody response between those positive and those negative for HLA-B27. The finding of longer duration of arthritis in the untreated patients who were positive for HLA-B27 compared with those who were negative is interesting, but it is based on only a limited number of patients.

Patients with reactive arthritis seldom ask for medical care because of enterocolitic symptoms. ${ }^{1}$ This agrees with our findings that patients with arthritis associated with yersinia have milder enterocolitic symptoms compared with patients with uncomplicated enterocolitis (unpublished data). It should, however, be remembered that the onset of entercolitis often occurs a couple of weeks before the arthritic symptoms cause the patient to attend hospital. Consequently, symptoms of enterocolitis could be overshadowed by the predominating arthritis and thus not reported by the patient. Only three of our 40 patients were admitted to hospital because of diarrhoea and fever. However, arthritis developed before an aetiological diagnosis was obtained.

The short duration of the IgA antibody response and, to some extent, also of that of IgG in our patients contrasts with the findings of Toivanen et al, who found a persistent IgG and IgA response in arthritic patients. ${ }^{16}$ This has, however, been refuted by other investigators. ${ }^{17}$ A persistence of IgG and IgA may still apply to antibodies against proteinous antigens as some patients' serum samples in our previous study were shown by immunoblotting to have persistent IgA response to non-lipopolysaccharide antigens. ${ }^{18}$ This was, however, with the exception of one antigen, true for both arthritic and non-arthritic patients.

In most reports of arthritis caused by $Y$ entercolitica the frequency of faecal isolates is very low. In this study it was possible to grow cultures of $Y$ enterocolitica in about half of the patients. Many explanations can be given-for example, greater awareness of the bacteriological laboratory and the performance of early stool culture in patients with reactive arthritis because of the ongoing study. Our culture methods did not differ from those of others, and we isolated $Y$ enterocolitica without cold enrichment. All patients positive for $Y$ enterocolitica, both treated and not treated with antibiotics, had cleared the bacteria from the stool by the first check up.

Patients with reactive arthritis with a positive faecal culture had higher peak $\operatorname{IgM}$ and, especially, IgA concentrations compared with those with a negative culture. This may indicate that these patients were investigated earlier in their disease process, when they still were in an early antibody response phase. This is substantiated by the finding that the peak IgG concentration did not differ between the two groups.

There were seven patients with erythema nodosum. All these patients were negative for HLA-B27, indicating different pathogenetic mechanisms from those in reactive arthritis. ${ }^{19}$

In conclusion, this study shows that short term early antibiotic treatment did not reduce the duration or severity of arthritic symptoms in patients with arthritis after enteric infection nor did it affect the serological or acute phase response in these patients. The presence of HLA-B27 did not have any impact on the clinical outcome. Based on these findings we conclude that short term antibiotic treatment of reactive arthritis associated with enteric infection has no beneficial effect on clinical outcome.

We thank Ms Anna-Lena Jönsson and Ms Anita Johansson for skilled technical help and Erik Leander for statistical advice. The investigation was supported by grants from the King Gustaf V 80 years fund, Riksförbundet mot Reumatism, the county council of Östergötland, and University Hospital, Linköping, Sweden.

I Toivanen A, Granfors K, Lahesmaa-Rantala R, Leino R, Ståhlberg T, Vuento $R$. Pathogenesis of yersinia-triggered reactive arthritis: immunological, microbiological and clinical aspects. Immunol Rev 1985;86:687-90.

2 Hoogkamp-Korstanje JAA, de Koning J, Heesemann J. Persistence of Yersinia enterocolitica in man. Infection 1988;16:81-5.

3 Granfors K, Jalkanen S, von Essen R, et al. Yersinia antigens in synovial-fluid cells from patients with reactive arthritis. N Engl f Med 1989;320:216-21.

4 de Koning J, Heesemann J, Hoogkamp-Korstanje JAA, Festen JJM, Houtman PM, van Oijen PLM. Yersinia in intestinal biopsy specimens from patients with seronegative spondyloarthropathy: correlation with specific serum IgA antibodies. F Infect Dis 1989;159:109-12.

5 Pott H-G, Wittenborg A, Junge-Hülsing G, Long-term antibiotic treatment in reactive arthritis. Lancet 1988; ; 245-6.

6 Marsal L, Winblad S, Wollheim F. Yersinia enterocolitica arthritis in southern Sweden: a four-year follow up study. BMF 1981;283:101-3.

7 Terasaki PI, Singal DP. Human histocompatibility antigens of leukocytes. Ann Rev Med 1969;20:175-88.

8 Ritchie DM, Boyle IA, McInnes, et al. Clinical studies with an articular index for the assessment of joint tenderness in patients with rheumatoid arthritis. Quart f Med 1968;37:393-404.

9 Lindberg AA, Holme T. Evaluation of some extraction methods for the preparation of bacterial polysaccarides for structural analysis. Acta Pathol Microbiol Immunol Scand [B] 1972;80:751-9.

10 Svedhem Å, Gunnarsson H, Kaijser B. Diffusion-in-gel enzyme-linked immunosorbent assay for routine detection of $\operatorname{IgG}$ and $\operatorname{IgM}$ antibodies to Campylobactr jejuni. F Infect Dis 1983;148:82-92.

1 Lehman, LE. Nonparametrics. In: Statistical methods based on ranks. San Francisco, California: Holden-Day, 1975.

Keat A. Reiters syndrome and reactive arthritis in perspective. $N$ Engl $\mathcal{F}$ Med 1983;309:1606-15.

13 Keat A. HLA-linked disease susceptibility and reactive arthritis. $f$ Infect 1982:5:227-39.

14 Svantesson B, Thorén A, Castor B, et al. Acute diarrhoea in adults: aetiology, clinical appearance and therapeutic aspects. Scand $\mathcal{F}$ Infect Dis 1988;20: clinical

15 Granfors K, Vilianen M, Tiilikainen A, Toivanen A. Persistence of IgM, IgG, and IgA antibodies to yersinia in yersinia arthritis. F Infect Dis 1980;141: 424-9.

16 Toivanen A, Lahesmaa-Rantala R, Vuento R, Granfors K. Association of persisting IgA response with yersinia triggered reactive arthritis: a study on 104 patients. Ann Rheum Dis 1987;46:898-901.

17 Mattila PS, Valtonen V, Tuori M-R, Mäkelä O. Antibody responses in arthritic and uncomplicated Yersinia enterocolitica infections. $\mathcal{J}$ Clin Immunol 1985;5:404-11.

18 Grönberg A, Frydén A, Kihlström E. Humoral immune response to individual Yersinia enterocolitica antigens in patients with and without reactive arthritis. Clin Exp Immunol 1989;76:361-5.

19 Linssen A, Feltkamp TEW. B27 positive disease versus B27 negative diseases. Ann Rheum Dis 1988:47:431-9.

(Accepted 14 September 1990) 